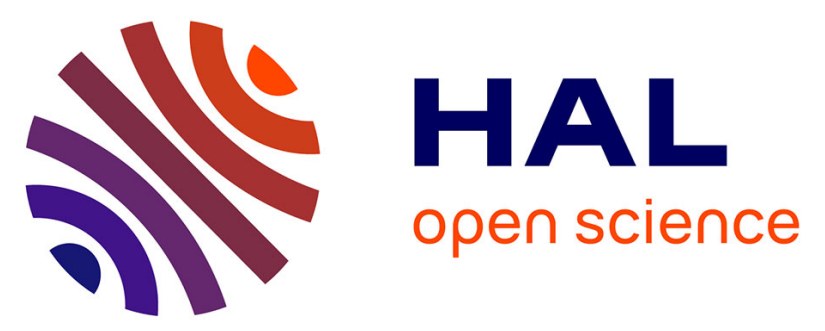

\title{
Intravenous high-dose methotrexate based systemic therapy in the treatment of isolated primary vitreoretinal lymphoma: an LOC network study
}

Marion Lam, Valérie Touitou, Sylvain Choquet, Nathalie Cassoux, Hervé Ghesquières, Laurent Kodjikian, Anna Schmitt, Sarra Gattoussi, Émeline Tabouret, Magali Sampo, et al.

\section{To cite this version:}

Marion Lam, Valérie Touitou, Sylvain Choquet, Nathalie Cassoux, Hervé Ghesquières, et al.. Intravenous high-dose methotrexate based systemic therapy in the treatment of isolated primary vitreoretinal lymphoma: an LOC network study. American Journal of Hematology, 2021, 96 (7), pp.823-833. 10.1002/ajh.26199 . hal-03228816

\section{HAL Id: hal-03228816 https://hal.science/hal-03228816}

Submitted on 11 Jun 2021

HAL is a multi-disciplinary open access archive for the deposit and dissemination of scientific research documents, whether they are published or not. The documents may come from teaching and research institutions in France or abroad, or from public or private research centers.
L'archive ouverte pluridisciplinaire HAL, est destinée au dépôt et à la diffusion de documents scientifiques de niveau recherche, publiés ou non, émanant des établissements d'enseignement et de recherche français ou étrangers, des laboratoires publics ou privés. 


\section{Intravenous high-dose methotrexate based systemic therapy in the treatment of isolated primary vitreoretinal lymphoma: an LOC network study}

Marion Lam, ${ }^{1,2}$ Valérie Touitou ${ }^{1}$ (MD, PhD), Sylvain Choquet $^{3}$ (MD, PhD), Nathalie Cassoux ${ }^{4}$ (MD, $\mathrm{PhD}$ ), Hervé Ghesquières ${ }^{5}(\mathrm{MD}, \mathrm{PhD})$, Laurent Kodjikian ${ }^{6,7}$ (MD, PhD), Anna Schmitt ${ }^{8}(\mathrm{MD})$, Sarra Gattoussi $^{9,10}(M D)$, Émeline Tabouret ${ }^{11,12}(M D)$, Magali Sampo ${ }^{13}(M D)$, Marie Blonski ${ }^{14}(M D)$, Karine Angioi-Duprez $^{15}$ (MD, PhD), Roch Houot ${ }^{16}$ (MD, PhD), Frédéric Mouriaux ${ }^{17}$ (MD, PhD), Emmanuel $\operatorname{Gyan}^{18}$ (MD, PhD), Marie-Laure Le Lez ${ }^{19}(\mathrm{MD})$, Marie-Pierre Moles $^{20}$ (MD), Fabien Croisé21 (MD), Adrien Chauchet $^{22}$ (MD), Claire Schwartz ${ }^{23}$ (MD), Guido Ahle ${ }^{24}$ (MD), Laurent Meyer ${ }^{25}$ (MD), Rémy Gressin $^{26}$ (MD), Christophe Chiquet ${ }^{27,28}$ (MD, PhD), Lucie Oberic ${ }^{29}$ (MD), Priscille Ollé ${ }^{30}$ (MD), JeanPierre Marolleau ${ }^{31}$ (MD, PhD), Benjamin Jany ${ }^{32}$ (MD), Adrian Tempescul ${ }^{33}$ (MD, PhD), Béatrice Cochener $^{34}$ (MD, PhD), Gandhi Damaj35 (MD, PhD), Jean-Claude Quintyn ${ }^{36}$ (MD, PhD), Cécile Chabrot $^{37}(M D)$, Eve Rousseau ${ }^{38}(M D)$, Paul Franciane ${ }^{39}(M D)$, Christelle Schneider ${ }^{40}(M D)$, Hélène Massé $^{41}(M D)$, Jérôme Tamburini Bonnefoy ${ }^{42}$ (MD, PhD), Antoine Brézin ${ }^{43}$ (MD, PhD), Luc-Matthieu Fornecker $^{44}$ (MD, PhD), Laurent Ballonzoli45 (MD), Magali Le Garff-Tavernier ${ }^{46}$ (PharmD, PhD), Khê Hoang-Xuan ${ }^{47}$ (MD, PhD), Bahram Bodaghi ${ }^{1}$ (MD, PhD), Carole Soussain ${ }^{48}$ (MD, PhD), Caroline Houillier $^{47}(M D)$

${ }^{1}$ Ophthalmology, Assistance Publique - Hôpitaux de Paris (APHP), Groupe Hospitalier PitiéSalpêtrière, Paris, France

${ }^{2}$ Sorbonne Université, Paris, France

${ }^{3}$ Hematology, APHP, Groupe Hospitalier Pitié-Salpêtrière, Sorbonne Université, Paris, France

${ }^{4}$ Ophthalmology, Institut Curie, Site Paris, Université Paris V Descartes et PSL (Paris Science et Lettre), Paris, France

${ }^{5}$ Hematology, Centre Hospitalier Lyon Sud, Université Claude Bernard Lyon 1, Pierre-Bénite, France ${ }^{6}$ Ophthalmology, Croix-Rousse University Hospital, Université Claude Bernard Lyon 1, Lyon, France ${ }^{7}$ Laboratoire UMR-CNRS 5510 Matéis, Université Lyon 1, Villeurbane, France

${ }^{8}$ Oncology, Institut Bergonié, Bordeaux, France

${ }^{9}$ Ophthalmology, Centre Hospitalier Universitaire de Bordeaux, France

${ }^{10}$ University of Bordeaux, INSERM, BPH, U1219, F-33000 Bordeaux, France

${ }^{11}$ Neuro-oncology, Assistance Publique - Hôpitaux de Marseille (AP-HM), Timone, Marseille, France

${ }^{12}$ Aix-Marseille Université, CRO2, UMR911, Marseille, France

${ }^{13}$ Ophthalmology, Centre Hospitalier Intercommunal Toulon, France

${ }^{14}$ Neurology, Centre Hospitalier Universitaire de Nancy, France

${ }^{15}$ Ophthalmology, Centre Hospitalier Universitaire de Nancy, Université de Lorraine, Nancy, France

This article has been accepted for publication and undergone full peer review but has not been through the copyediting, typesetting, pagination and proofreading process which may lead to differences between this version and the Version of Record. Please cite this article as doi: $10.1002 /$ ajh.26199 
${ }^{16}$ Hematology, Centre Hospitalier Universitaire de Rennes, Université de Rennes, INSERM U1236, Rennes, France

${ }^{17}$ Ophthalmology, Centre Hospitalier Universitaire de Rennes, France

${ }^{18} \mathrm{Hematology}$, Centre Hospitalier Universitaire de Tours, France

${ }^{19}$ Ophthalmology, Centre Hospitalier Universitaire de Tours, France

${ }^{20}$ Hematology, Centre Hospitalier Universitaire de Angers, France

${ }^{21}$ Ophthalmology, Centre Hospitalier Universitaire de Angers, France

${ }^{22}$ Hematology, Centre Hospitalier Universitaire de Besançon, Hôpital Jean Minjoz, Besançon, France

${ }^{23}$ Ophthalmology, Centre Hospitalier Universitaire de Besançon, Hôpital Jean Minjoz, Besançon,

France

${ }^{24}$ Neurology, Hôpital Pasteur - Hôpitaux civils de Colmar, France

${ }^{25}$ Ophthalmology, Hôpitaux civils de Colmar, France

${ }^{26}$ Hematology, Centre Hospitalier Universitaire de Grenoble, France

${ }^{27}$ Grenoble Alpes University, Grenoble, France

${ }^{28}$ Ophthalmolgy, Grenoble Alpes University Hospital, Grenoble, France

${ }^{29}$ Hematology, Institut Universitaire du Cancer de Toulouse Oncopôle, Toulouse, France

${ }^{30}$ Ophthalmology, Ramonville Saint Agne, France

${ }^{31}$ Hematology, Centre Hospitalier Universitaire de Amiens, France

${ }^{32}$ Ophthalmology, Centre Hospitalier Universitaire de Amiens, France

${ }^{33} \mathrm{Hematology}$, Centre Hospitalier Universitaire de Brest, France

${ }^{34}$ Ophthalmology, Centre Hospitalier Universitaire de Brest, France

${ }^{35} \mathrm{Hematology}$, Centre Hospitalier Universitaire de Caen, Université de Caen-Normandie, France

${ }^{36}$ Ophthalmology, Unicaen, Centre Hospitalier Universitaire de Caen, France

${ }^{37}$ Hematology, Centre Hospitalier Universitaire de Clermont-Ferrand, France

${ }^{38}$ Ophthalmology, Centre Hospitalier Universitaire de Gabriel Montpied, Clermont-Ferrand, France

${ }^{39}$ Hematology, Saint Eloi Hospital, Montpellier University Hospital, France

${ }^{40}$ Ophthalmology, Centre Hospitalier Universitaire Gui de Chauliac, Montpellier, France

${ }^{41}$ Ophthalmology, Centre Hospitalier Universitaire de Nantes, France

${ }^{42}$ Hematology, APHP, Cochin Hospital, Paris, France

${ }^{43}$ Ophthalmology, APHP, Cochin Hospital, Paris, France

${ }^{44}$ Hematology, Centre Hospitalier Universitaire de Strasbourg, France

${ }^{45}$ Ophthalmology, Centre Hospitalier Universitaire de Strasbourg, France

${ }^{46}$ Service d'hématologie biologique, APHP, Groupe Hospitalier Pitié-Salpêtrière, Paris, France

${ }^{47}$ Neurology, APHP, Sorbonne Université, IHU, ICM, Groupe Hospitalier Pitié-Salpêtrière, Paris, France

${ }^{48}$ Hematology, Institut Curie, Site Saint-Cloud, France ; INSERM U932, Institut Curie, PSL Research University, Paris 75005, France 
Corresponding author: Caroline Houillier, MD, caroline.houillier@aphp.fr. Neuro-Oncology

Department, Pitie Salpetriere Hospital, 83 boulevard de l'Hopital, 75013, Paris, France. Phone :

+33142164160, Fax : +33142160459

\section{Data availability}

All the data are available in the national French database of the "Lymphome Oculo-Cérébral" (LOC) network.

\section{Funding information}

The authors received no specific funding for this work.

\section{Conflict of interest disclosure}

S. Choquet declares conflict of interest with Roche, Janssen, Celgène, Abbvie, Sandoz, Biogaran and Accord Healthcare. L. Kodjikian declares conflict of interest with Abbvie, Allergan, Bayer, Novartis, Roche and Thea. P. Franciane declares conflicts of interest with Novartis. All other authors declare no competing interests regarding this study.

\section{Ethics approval statement}

The study was approved by the Institutional Ethical Committee of the coordinating center on the 04/24/2018 and by the French "Commission Nationale de l'Informatique et des Libertés" (CNIL) ( $\left.{ }^{\circ} 913170\right)$. This study was conducted in accordance with the Declaration of Helsinki.

\section{Patient consent statement}

All patients gave informed consent for the submission of their data to the database.

Short running title: Intravenous methotrexate in vitreoretinal lymphoma

Keywords: primary vitreoretinal lymphoma, high-dose methotrexate, prognosis

Abstract word count: 250 words

Main text word count: 3654 words

3 tables

1 figure

Supplementary data : 1 table, 1 figure 


\section{Abstract}

The treatment of primary vitreoretinal lymphoma (PVRL) remains controversial regarding the use of local, systemic, or combined treatments. The aim of this study was to analyze the efficacy and toxicity of intravenous high-dose methotrexate (IV HD-MTX) based systemic therapy in a uniformly treated population of PVRL patients.

From a nationwide French database, we retrospectively selected 59 patients (median age: 70 years, median Karnofsky Performance Status: 90\%) with isolated PVRL at diagnosis who received first-line treatment with HD-MTX between 2011-2018. 8/59 patients also received a local treatment. No deaths or premature discontinuations of MTX due to toxicity were reported. A complete response was obtained in 40/57 patients after chemotherapy. Before treatment, IL-10 was elevated in the aqueous humor $(\mathrm{AH})$ or in the vitreous in $89 \%$ of patients. After treatment, $\mathrm{AH}$ IL-10 was undetectable in $87 \%$ of patients with a CR/uCR/PR and detectable in $92 \%$ of patients with PD/SD. After a median follow-up of 61 months, 41/59 (69\%) patients had relapsed, including 29 isolated ocular relapses as the first relapse and a total of 22 brain relapses. The median overall survival, progression-free survival, ocularfree survival and brain-free survival were $75,18,29$ and 73 months, respectively.

IV HD-MTX based systemic therapy as a first-line treatment for isolated PVRL is feasible, with acceptable toxicity, even in an elderly population. This strategy seems efficient to prevent brain relapse with prolonged overall survival. However, the ocular relapse rate remains high. New approaches are needed to improve local control of this disease, and ocular assessment could be completed by monitoring AH IL-10. 


\section{Introduction}

Primary vitreoretinal lymphoma (PVRL) is a rare malignancy that belongs to the larger group of primary central nervous system lymphomas (PCNSLs). PVRL affects mostly adults from the third to the eighth decades ${ }^{1,2}$. PVRL arises in the vitreous and/or retina and is most often a diffuse large $\mathrm{B}$-cell lymphoma (DLBCL). Although often clinically indolent, the prognosis of the disease is poor and mainly related to the risk of relapse in the brain. Approximately 42 to $92 \%$ of PVRLs will have cerebral involvement within 8 to 37 months of diagnosis ${ }^{3-5}$. Several studies have shown that the median overall survival of patients with isolated PVRL is much longer than that of patients who have intraocular disease associated with cerebral involvement (37-58 months compared to 18-34 months) ${ }^{3,6-8}$.

Although much progress has been made in the treatment of cerebral lymphoma, the treatment of isolated PVRL is still controversial because of the absence of prospective comparative studies regarding local treatment (i.e., intravitreal chemotherapy or ocular radiotherapy), systemic chemotherapy or a combination of local and systemic treatment. In 2011, the International Primary Central Nervous System Lymphoma Collaborative Group (IPCG) recommended local treatment for unilateral disease and local or extensive treatment (chemotherapy and local treatment) for bilateral disease $^{9}$. The British Neuro-Oncology Society recommended intravenous high-dose methotrexate (IV HD-MTX) combined with ocular and brain radiotherapy for the treatment of PVRL ${ }^{10}$ based on several studies of combined treatment in patients with $\mathrm{PCNSL}^{11,12}$ and suggested intravitreal injection of methotrexate for patients with recurrent disease confined to the eyes as an effective option ${ }^{13}$. In 2015, the European Association for Neuro-Oncology stated that either local or systemic treatments could be options for PVRL treatment and that the decision should be made according to the individual risk of treatment toxicities and local expertise. Ocular radiotherapy and intravitreal chemotherapy are associated with good response rates and a variable rate of ocular relapse (0-61\%) but do not seem to change the risk of secondary cerebral involvement and therefore overall survival ${ }^{3,14-19}$. Systemic chemotherapy seems promising in the prevention of cerebral involvement, as reported in several recent studies ${ }^{8,15}, 20,21$, but therapeutic options included in the systemic chemotherapy arm were very different, and data about IV HD-MTX-based chemotherapy are scarce.

In France, a national expert network (the LOC network) was created in 2011 to standardize the treatment plan for PCNSL nationwide. This network issued national recommendations based on the literature regarding the management of PCNSL. For isolated PVRL, the recommendation was to treat all patients with fair general condition with IV HD-MTX based systemic therapy and to treat patients with worse condition with ocular radiotherapy or intravitreal MTX. Regarding follow-up, the recommendation was to perform an ophthalmological examination every 2 or 3 months during the treatment, then every 6 months during the first 2 years after the treatment and once a year thereafter 
and to measure interleukin-10 (IL-10) levels in the aqueous humor ( $\mathrm{AH})$ at baseline, at the end of the treatment and in the case of any doubt of ocular relapse.

The aim of this study was to analyze ocular and systemic efficacy and toxicity in a population of patients with isolated PVRL who uniformly received first-line treatment with IV HD-MTX based systemic therapy.

\section{Methods}

This work is based on an analysis of the French LOC network database ${ }^{22}$, a nationwide database centralizing information from 28 expert centers for the management of PCNSL in France. The database was approved by the Institutional Ethical Committee of the coordinating center and by the French "Commission Nationale de I'Informatique et des Libertés" (CNIL). All patients gave informed consent for the submission of their data to the database. This study was conducted in accordance with the Declaration of Helsinki. No conflict of interest has been reported, and no private funds were used.

Patients were retrospectively selected according to the following criteria: 1) isolated PVRL at initial diagnosis (at baseline, all patients had at least a cerebral MRI and a full-body CT scan or FDGPET scan to exclude cerebral and systemic involvement); 2) diagnosis confirmed by cytopathological examination of a vitreous sample; 3) age $>18$ years; 4) immunocompetent status; and 5) IV HD-MTXbased chemotherapy as first-line treatment (MTX $\geq 1 \mathrm{~g} / \mathrm{m} 2$ ). Patients with asymptomatic meningeal involvement were not excluded. Patients were selected in March 2018, and data were analyzed in September 2020.

The toxicity of chemotherapy was assessed according to the Common Terminology Criteria for Adverse Events version 5. Response to therapy was assessed according to the IPCG criteria ${ }^{26}$ with the following criteria: complete response (CR): no evidence of residual disease in the anterior chamber, vitreous or retina; uncertain complete response (UCR): minor nonspecific anomalies in ophthalmological findings; partial response (PR): $>50 \%$ reduction in ophthalmological findings; progressive disease (PD): a worsening of the ocular findings or new ocular lesions; and stable disease (SD): none of the previous items. Ocular relapse was defined clinically by recurrent or new ocular disease in the anterior chamber, vitreous or retina. Assessment of ocular response can be difficult after vitrectomy and could only be classified as complete response or progression in some cases. IL-10 at diagnosis was considered elevated with a cutoff of $30 \mathrm{pg} / \mathrm{ml}$ in the aqueous humor and of 65 $\mathrm{pg} / \mathrm{ml}$ in the vitreous for the diagnosis of PVRL according to previous publications $\mathrm{s}^{23-25}$. IL-10 in the AH was also monitored at the end of the treatment and during the follow-up at the discretion of the physicians. IL-10 levels were classified as detectable $(\geq 2.5 \mathrm{pg} / \mathrm{ml})$ or undetectable $(<2.5 \mathrm{pg} / \mathrm{ml})$ for the follow-up. Long-term responders were defined as patients who have never relapsed during the followup, with a minimum of 2 years-follow-up after first-line chemotherapy and non-responders were defined as patients who relapsed either during or at the end of first-line chemotherapy or within the 6 months after chemotherapy. 
The four main endpoints were overall survival (OS), progression-free survival (PFS), ocularfree survival (OFS) and brain-free survival (BFS), calculated from the date of the cytopathological diagnosis. PFS was defined as the time without relapse (regardless of location) or without death (regardless of cause). BFS and OFS were defined as the time without brain and ocular relapse, respectively. Brain imaging was routinely performed once a year according to the national recommendation of the LOC network, and at any time in case of symptoms. Survival rates were calculated using the Kaplan-Meier method. The log-rank test was used to test for the equality of the PFS, BFS and OS distributions. A multivariate analysis was performed with the multivariate Cox proportional hazards regression model. Age and Karnofsky Performance Status (KPS) score, known as the main prognostic factors in PCNSL, were included in the multivariate analysis, as well as the variables with significant prognostic value in the univariate analysis. Two-sided $p$ values $<0.05$ were considered significant. All statistics were performed with xlstat software 2019.3.2.

\section{Results}

\section{Patients characteristics at diagnosis}

Of the 1534 patients with PCNSL diagnosed between January 2011 and March 2018 included in the database, 69 patients had isolated PVRL (4.5\%). Ten patients were excluded because they received only local treatment $(\mathrm{N}=5)$ or non-IV HD-MTX-based systemic chemotherapy $(\mathrm{N}=5)$. Fifty-nine patients (76\% women) met the inclusion criteria. Their main characteristics are reported in table 1 . The median age was 70 years (range: 39-88), and the median KPS score was 90\% (range, 60-100). There was bilateral ocular involvement in 39/59 (66\%) patients. All the patients underwent vitrectomy. Eight of 59 patients had a second vitrectomy in the fellow eye because of a first negative vitrectomy (vitrectomy in 67 eyes). There was a pathological diagnosis of DLBCL in $97 \%$ of patients. In total, $89 \%$ (39/44) and $89 \%(42 / 47)$ of the patients had elevated IL-10 in the aqueous humor ( $\mathrm{AH})$ and vitreous, respectively. Lymphomatous cells were found in the CSF of $4 / 48$ patients (8\%).

\section{Treatment}

The median duration between the diagnosis and the beginning of treatment was 48 days (range 3229). The chemotherapy protocols are listed in table 1 . A total of $52 / 59$ patients $(88 \%)$ received $\geq 3$ $\mathrm{g} / \mathrm{m}^{2}$ IV HD-MTX per injection, with a median dose of $3 \mathrm{~g} / \mathrm{m}^{2}$ (range 1-8 $\mathrm{g} / \mathrm{m}^{2}$ ) and a median number of 6 injections. Rituximab $\left(375 \mathrm{mg} / \mathrm{m}^{2}\right)$ was administered to $39 / 59$ patients $(66 \%)$. A total of $8 / 59(13 \%)$ patients received local treatment combined with systemic chemotherapy, consisting of consolidation ocular radiotherapy (RT) in 6 patients (30 Gray) and intravitreal MTX in 2 patients who received 3 injections and 37 injections, respectively. 


\section{Outcomes}

The main outcomes are indicated in table 2.

\section{Response to chemotherapy}

At the end of chemotherapy, 40/57 patients (70\%) and 71/95 (75\%) eyes had a complete response (CR) or an unconfirmed complete response (UCR), while 13/57 (23\%) patients and 18/95 eyes (19\%) showed cancer progression. The response was not assessable in 2 patients ( 3 eyes), due to a lack of data for one patient, and death due to myocardial infarction during the treatment for one patient. Bestcorrected visual acuity improved in 41/83 affected eyes, worsened in 17/83 eyes, and remained stable in $23 / 83$ eyes. Median visual acuity significantly improved after chemotherapy (logMar 0.10 after treatment versus 0.22 before treatment, $p=0.04$ ). At the end of first-line chemotherapy, AH IL-10 levels were detectable in $3 / 23$ patients (13\%) with a CR or UCR (23 data points available among 40 patients with a CR/uCR); 2 of them relapsed in the eye two months after chemotherapy, and the $3^{\text {rd }}$ patient experienced brain relapse one year after chemotherapy. AH IL-10 levels were detectable in 12/13 patients with PD (median $31 \mathrm{pg} / \mathrm{ml}$, range 5-594) and undetectable in 1/13 patients with PD whose IL10 levels were never elevated. AH IL-10 levels were undetectable in 1/1 of PR patient who never relapsed.

\section{Toxicity}

Grade III-IV myelotoxicity was observed in $27 / 51$ patients (53\%). Only $3 / 51(6 \%)$ patients had febrile neutropenia. Grade III-IV hepatic cytolysis and renal toxicity were observed in 4/51 (8\%) and 4/51 $(8 \%)$ patients, respectively. No ocular toxicity was reported from systemic chemotherapy. No deaths or disruptions of therapy due to toxicity were reported after the initial HD-MTX-based chemotherapy, but a reduction in the dose of MTX was reported in 5/51 (10\%) patients due to grade III-IV renal or liver toxicities. The dose of cytarabine and vincristine were decreased in 3/52 (6\%) patients and 2/52 (4\%) patients, respectively. Otherwise, the patients completed all the treatments as per those treatment protocols. One case of endophthalmitis and one case of retinal detachment were reported following vitrectomy. No ocular complications due to anterior chamber puncture were reported. After intravitreal MTX, cataract and keratopathy were reported in $2 / 2$ patients and $1 / 2$ patient, respectively. After ocular radiotherapy, dry eyes, cataract, radiation retinopathy and macular edema were reported in 2/6, 3/6, $1 / 6$ and $1 / 6$ patients respectively.

\section{Relapses}

With a median follow-up of 61 months (Cl 95\% 50-71), $42 / 59$ (71\%) patients relapsed during the follow-up. Thirty-four/59 (58\%) patients had at least one ocular relapse, including 17/59 (29\%) patients who had only isolated ocular relapses and 22/59 (37\%) patients who had brain relapse. For patients who had both ocular and cerebral relapses, the first relapse was ocular in $79 \%$ of the cases. Only one patient who initially had meningeal involvement experienced brain relapse 73 months after diagnosis. 
The only patient who has received high-dose chemotherapy with autologous stem cell transplantation (HCT-ASCT) in first-line treatment never relapsed and is still in complete remission 9.5 years after diagnosis.

Among patients whose first relapse was ocular ( $n=33)$, AH IL-10 levels were available in 27 patients, and AH IL-10 levels were increased in 25/27 patients (93\%) and were undetectable in 2/27 patients (7\%). Of the 6 patients with ocular radiotherapy, none had ocular relapse, but three had brain relapse. The 2 patients who received intravitreal MTX never relapsed.

\section{Survival}

The median PFS was 18 months ( $\mathrm{Cl}$ 95\% 12-37). The median BFS was 73 months (CI 95\% 48-NR). The median OS was 75 months (CI 95\% 68-NR). The 5-year cumulative OS rate was $67 \%(95 \% \mathrm{Cl}$, 53- 80\%) (Figure 1). Twenty/59 patients (34\%) died during the study, and 17 died due to cerebral progression of lymphoma.

\section{Treatment of the relapses}

Twenty-seven of forty-two patients received only systemic treatment, 10/42 received combined treatment (local and systemic), and 4/42 did not receive any treatment. The treatment was unknown for one patient. Altogether, 14/42 (33\%) patients received lenalidomide, $17 / 42$ (40\%) patients received ibrutinib, 18/42 (43\%) patients received temozolomide and 11/42 (26\%) patients received HD-MTXbased chemotherapy in the course of the disease. One patient received cerebral radiotherapy, and 11/42 (26\%) patients received high-dose chemotherapy with HCT-ASCT (7 for ocular relapse, 2 for cerebral relapse and 2 for ocular and cerebral relapse). Among them, 7 patients were still in complete response at the time of analysis after a median follow-up for HCT-ASCT of 24 months, while 4 patients relapsed 7, 15, 21 and 39 months after HCT-ASCT, respectively. All patients with ocular relapse treated locally (6/42) relapsed and then received systemic treatment.

\section{Prognostic factors}

The main prognostic factors for OS are indicated in table 3 . Only age $<70$ years and an HD-MTX dose $\geq 3 \mathrm{~g} / \mathrm{m}^{2} /$ injection were associated with better OS in both univariate and multivariate analyses, while KPS score, AH or vitreous IL-10 levels at baseline, type of HD-MTX based protocol or combination with local treatment were not associated with prognosis (supplementary data figure 1). OS after relapse was 29 months when the first relapse was cerebral (+/- ocular), while it was 55 months when the first relapse was only ocular $(p=0.0004)$. Combination with local treatment was associated with a better OFS (55 versus 18 months, $p=0.02$ ) but did not change the OS, BFS or PFS ( $p=0.2, p=0.2$ and $p=0.1$, respectively). Levels of IL-10 in the vitreous or the aqueous humor at diagnosis did not predict ocular or CNS relapse. Unilateral vs bilateral ocular involvement had no significant impact in terms of BFS or OS. OS and BFS were comparable between the three treatment protocols (i.e (R)-MPV-(A), (R)-MBVP-(A) and (R)-MA), whereas OFS was better in the (R)-MBVP-(A) group compared to (R)- 
MPV-(A) and (R)-MA groups, (median OFS of 51 months versus 24 and 9 months, respectively, $\mathrm{p}=0.002$ ). However, patients were younger in the (R)-MBVP-(A) group (median age of 59, 74 and 70 years, respectively, $\mathrm{p}=0.004$ ).

There was no difference between the long-term responder group $(n=16)$ and the non-responder group $(n=13)$ in terms of clinical and treatment characteristics.

\section{Discussion (supplementary data table 1)}

To our knowledge, this study represents the largest series of isolated PVRL reporting the outcome of patients uniformly treated with IV HD-MTX based systemic therapy as the first line of treatment according to the French national recommendations. This series represents a real-life population of patients with isolated PVRL, as almost $90 \%$ of the patients with PVRL diagnosed between 2011 and 2018 in the LOC network received HD-MTX-based chemotherapy and were therefore included in the study. Chemotherapy protocols were similar to those used for PCNSL. Whereas the majority of the population was elderly (median age of 70 years), IV HD-MTX-based chemotherapy seemed to be feasible, with an acceptable level of toxicity. Most patients received $\geq 4$ injections of MTX at a dose per injection $\geq 3 \mathrm{~g} / \mathrm{m}^{2}$. No deaths or disruptions of therapy due to MTX toxicity were reported.

Despite a high percentage of patients with CR/uCR (70\%), we report a high rate of ocular relapses (58\%), compared to rates of $22 \%$ and $25 \%$ in the two largest series in the literature ${ }^{8,27}$. This high rate of ocular relapse probably explains why our median PFS is lower than that in most other series (18 months versus 30-46 months in the literature) ) $^{6,728,29}$. This result might be due to the small percentage of patients with local treatment combined with systemic chemotherapy in our series. Some studies have suggested that although IV HD-MTX has good penetration through the blood-ocular barrier and the blood-brain barrier, the penetration of MTX in the two organs might still differ, and the maintenance of high levels of MTX in the vitreous might be more difficult by IV administration than by direct intravitreal injection ${ }^{10,30-32}$. Furthermore, in our series, patients who received both local and systemic treatments had better ocular-free survival $(p=0.02)$. IV HD-MTX-based chemotherapy alone might not be sufficient to prevent ocular relapse. However, the rate of ocular relapse is quite variable in the literature. Recently, Ma et al. found an ocular relapse rate of $62 \%$ within 40 months of follow-up in 13 patients with isolated PVRL, although they received combined treatment with IV HD-MTX and intravitreal $\mathrm{MTX}^{33}$. Castellino et al. reported an ocular relapse rate of $46 \%$ in a series of $33 \mathrm{PVRL}$ patients comparing local, systemic and combined treatment ${ }^{28}$.

Another hypothesis for the high rate of ocular relapse in our series could result from the close systematic monitoring recommended by the LOC expert network. The AH IL-10 level appears to be a very valuable marker in the follow-up of the disease, especially when ocular relapse is not clinically obvious. IL-10 and IL- 6 were the first cytokines shown to have proven value for the diagnosis of $\mathrm{PVRL}^{23,25}$, with a sensitivity and specificity of 0.78 and 0.97 , respectively, for an IL-10 cutoff of 30 
$\mathrm{pg} / \mathrm{ml}$ in the $\mathrm{AH}^{24}$ and of 0.93 and 1.0, respectively, for an IL-10 cutoff of $65 \mathrm{pg} / \mathrm{ml}$ in the vitreous. The ISOLD score, based on the levels of IL10 and IL6 in the AH and vitreous, has shown a sensitivity and specificity of 0.93 and 0.95 , respectively ${ }^{34}$. However, the value of IL-10 and IL-6 levels after treatment and at relapse is not yet clearly defined in the literature. Very small series have described a decrease in IL-10 levels in the AH after intravitreal MTX or rituximab ${ }^{32,35,36}$, but no data on IL-10 levels are

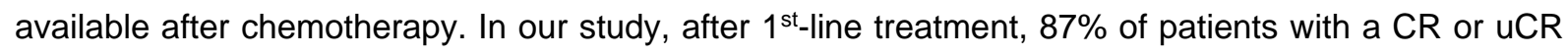
had undetectable IL-10 levels, whereas $92 \%$ of patients with SD/PD had detectable IL-10 levels. Compared to the gold-standard clinical IPCG criteria for defining a complete response, IL-10 levels were discordant in 4 patients. In 3 patients with a CR/UCR, IL-10 levels remained elevated, and 2 of them relapsed a few months after the end of the treatment. The third patient relapsed in the brain one year afterwards. Finally, one patient with PD had undetectable IL-10 levels, but IL-10 levels had never been elevated in his disease history, despite classic ophthalmological involvement with hyalitis. The IPCG criteria, based only on clinical issues, could therefore be easily met by the determination of IL-10 levels in the $\mathrm{AH}$.

Despite a high rate of ocular relapse and a short PFS, the median OS reported in this study seems higher than what was previously reported in the large series for which the treatment was not uniform: 75 months in our series versus 34-58 months ${ }^{7,8}$ (supplementary data table 1). The first explanation could be that the systematic use of HD-MTX based systemic therapy as $1^{\text {st-line }}$ treatment prevents brain relapse. The literature regarding the treatment of isolated PVRL, including almost exclusively retrospective studies, remains controversial regarding the use of local, systemic or local and systemic treatment. Regarding ocular radiotherapy, Mikami et al. and Teckie et al. found brain relapse rates of $55 \%$ and $42 \%$, respectively, in patients treated with ocular radiotherapy after a median follow-up time of 36 and 25 months $^{18,19}$. Berenbom et al. showed that the addition of chemotherapy to ocular radiotherapy delayed the onset of brain relapse in patients: the median BFS was 28 months with chemotherapy versus 8 months without $(p=0.24)^{15}$. Regarding intravitreal MTX, Akiyama et al. found a better two-year BFS with combined treatment (IV HD-MTX-based chemotherapy and intravitreal MTX) than with intravitreal MTX alone (58\% versus $38 \%$ ) and a rate of brain relapse for the intravitreal MTX alone group of $88 \%$ at the 40 -month follow-up ${ }^{21}$. Hashida et al. found that prophylactic IV HD-MTX-based chemotherapy delayed the onset of cerebral involvement in a series of 26 patients with PVRL (43 months with IV MTX-based chemotherapy versus 10 months with local treatment only (intravitreal injection of MTX or rituximab, $\mathrm{p}=0.0005)^{20}$.

Three large retrospective studies ${ }^{7,828}$, with 83,78 , and 33 patients with PVRL, respectively, compared systemic, local and combined treatment (supplementary data table 1). All three studies failed to show that systemic treatment was better than local treatment in terms of OS. However, the treatments received by the combined treatment group in those studies varied greatly and included chemotherapy and/or ocular radiotherapy and/or whole-brain radiotherapy and/or intrathecal chemotherapy and/or intravitreal MTX or rituximab. Furthermore, the proportions of patients receiving HD-MTX-based regimens among the three studies were not similar, with $70 \%, 40 \%$ and $30 \%$, 
respectively ${ }^{7,8,28}$. Our population was quite uniform in terms of treatment. Although OS was not different between treatment groups in Castellino et al.'s study, the author found that PFS and BFS were better with combined treatment $(p=0.002$ and $p=0.003)$.

Several studies with a smaller number of patients but uniformly receiving IV HD-MTX based systemic therapy showed encouraging results. Ma et al. and De la Fuente et al. described high rates of five-year overall survival of $68.8 \%$ and $80 \%$, respectively, close to our series (66\% at five years), using IV HD-MTX-based treatment combined with intravitreal MTX and ocular radiotherapy ${ }^{33,37}$. Kaburaki et al. found four-year BFS and OS of $90 \%$ and $89 \%$, respectively, using IV HD-MTX based systemic therapy, intravitreal MTX and whole-brain radiotherapy in a small series of 11 patients with PVRL ${ }^{38}$. Therefore, IV HD-MTX based systemic therapy might be efficient in preventing brain relapse and extending overall survival with or without the addition of local treatment.

The second explanation for the better OS in the present study could be the effectiveness of the treatment at relapse and the use of promising drugs in PVRL ${ }^{39-41}: 89 \%$ of the patients received at least one systemic salvage therapy, including ibrutinib, temozolomide or lenalidomide, in $40 \%, 43 \%$ and $33 \%$ of cases, respectively, and $26 \%$ of patients received HCT-ASCT. Further studies are needed to study these first-line drugs as single agents or in combination with HD-MTX. The use of these strategies in first-line treatment in combination with HD-MTX might also be interesting ${ }^{42}$.

This work had several limitations, mainly due to the inherent biases of a retrospective study and to some missing data. Furthermore, the follow-up could be longer in this disease with prolonged survival. We only have one group of treatments, so it is difficult to measure the exact benefit of HDMTX-based $1^{\text {st }-l i n e ~ t r e a t m e n t ~ c o m p a r e d ~ t o ~ l o c a l ~ t r e a t m e n t . ~ I t ~ i s ~ a l s o ~ d i f f i c u l t ~ i n ~ s u c h ~ a ~ r e t r o s p e c t i v e ~}$ study with heterogeneous HD-MTX based protocols to evaluate the impact of the drugs associated to MTX. Prospective and randomized studies would be very useful to progress in the management of PVRL but are very difficult to perform due to the rarity of the disease.

\section{Conclusion}

This "real-life" study shows that HD-MTX-based chemotherapy is feasible in PVRL, with an acceptable safety profile in an elderly population. Long-term BFS and OS rates were high, suggesting that this treatment strategy might be effective in preventing brain relapse. However, the rate of ocular relapse was disappointing. AH IL-10 levels should be included in the criteria for response and relapse for the early detection of ocular relapses.

In the future, the combination of HD-MTX based systemic therapy with local treatments or with drugs such as ibrutinib, lenalidomide or temozolomide might improve the prognosis of patients with PVRL. The role of intensive chemotherapy with autologous stem cell transplantation should also be addressed in this severe disease.

\section{Acknowledgments}


We gratefully thank the patients and their families for their participation in this study.

We acknowledge the research technicians of the LOC network (Bachir Aidoui, Diane Genet, Hassen Douzane, Yah-se Abada), all the members of the LOC network and the Institut National of Cancer (INCa).

\section{References}

1. Araujo I, Coupland SE. Primary Vitreoretinal Lymphoma-A Review. Asia-Pac J Ophthalmol. 2017;6:283- 289.

2. Aziz HA, Peereboom DM, Singh AD. Primary central nervous system lymphoma. Int Ophthalmol Clin. 2015;55:111- 121.

3. Cho B-J, Kim DY, Park UC, Lee JY, Yoon YH, Yu HG. Clinical Features and Treatment Outcomes of Vitreoretinal Lymphoma according to Its Association with CNS Lymphoma. Ocul Immunol Inflamm. 2018;26:365-371.

4. Klimova A, Heissigerova J, Rihova E, Brichova M, Pytlik R, Spicka I, et al. Combined treatment of primary vitreoretinal lymphomas significantly prolongs the time to first relapse. $\mathrm{Br} \mathrm{J}$ Ophthalmol. 2018;102:1579-1585.

5. Touitou V, LeHoang P, Bodaghi B. Primary CNS lymphoma. Curr Opin Ophthalmol. 2015;26:526- 533.

6. Kim MM, Dabaja BS, Medeiros J, Kim S, Allen P, Chevez-Barrios P, et al. Survival Outcomes of Primary Intraocular Lymphoma: A Single-institution Experience. Am J Clin Oncol. 2016;39:109- 113. 7. Grimm SA, Pulido JS, Jahnke K, Schiff D, Hall AJ, Shenkier TN, et al. Primary intraocular lymphoma: an International Primary Central Nervous System Lymphoma Collaborative Group Report. Ann Oncol Off J Eur Soc Med Oncol. 2007;18:1851- 1855.

8. Riemens A, Bromberg J, Touitou V, Sobolewska B, Missotten T, Baarsma S, et al. Treatment strategies in primary vitreoretinal lymphoma: a 17-center European collaborative study. JAMA Ophthalmol. 2015;133:191- 197.

9. Chan C-C, Rubenstein JL, Coupland SE, Davis JL, Harbour JW, Johnston PB, et al. Primary vitreoretinal lymphoma: a report from an International Primary Central Nervous System Lymphoma Collaborative Group symposium. The Oncologist. 2011;16:1589- 1599.

10. British Neuro-Oncology Society/NCAT Rare Tumor Guidelines. Guidelines on the diagnosis and management of primary CNS and intra-ocular Lymphoma (PCNSL). www.bnos.org.uk. accessed june 2011

11. DeAngelis LM, Seiferheld W, Schold SC, Fisher B, Schultz CJ, Radiation Therapy Oncology Group Study 93-10. Combination chemotherapy and radiotherapy for primary central nervous system lymphoma: Radiation Therapy Oncology Group Study 93-10. J Clin Oncol Off J Am Soc Clin Oncol. 2002;20:4643- 4648.

12. Abrey LE, DeAngelis LM, Yahalom J. Long-term survival in primary CNS lymphoma. J Clin Oncol Off J Am Soc Clin Oncol. 1998;16:859- 863. 
13. Helbig H, Cerny $\mathrm{T}$, de Smet MD. Intravitreal chemotherapy for intraocular lymphoma. Ophthalmol Z Dtsch Ophthalmol Ges. 2003;100:145- 149.

14. Frenkel S, Hendler K, Siegal T, Shalom E, Pe'er J. Intravitreal methotrexate for treating vitreoretinal lymphoma: 10 years of experience. $\mathrm{Br} \mathrm{J}$ Ophthalmol. 2008;92:383- 388.

15. Berenbom A, Davila RM, Lin H-S, Harbour JW. Treatment outcomes for primary intraocular lymphoma: implications for external beam radiotherapy. Eye. 2007;21:1198- 201.

16. Grimm SA, McCannel CA, Omuro AMP, Ferreri AJM, Blay J-Y, Neuwelt EA, et al. Primary CNS lymphoma with intraocular involvement: International PCNSL Collaborative Group Report. Neurology. 2008;71:1355- 1360.

17. Smith JR, Rosenbaum JT, Wilson DJ, Doolittle ND, Siegal T, Neuwelt EA, et al. Role of intravitreal methotrexate in the management of primary central nervous system lymphoma with ocular involvement. Ophthalmology. 2002;109:1709- 1716.

18. Mikami R, Nakayama H, Goto H, Kimura K, Usui Y, Nogi S, et al. Preliminary results of radiotherapy for primary intraocular non-Hodgkin lymphoma. Leuk Lymphoma. 2013;54:2181- 2184.

19. Teckie S, Yahalom J. Primary intraocular lymphoma: treatment outcomes with ocular radiation therapy alone. Leuk Lymphoma. 2014;55:795- 801.

20. Hashida N, Nakai K, Saitoh N, Nishida K. Association between ocular findings and preventive therapy with onset of central nervous system involvement in patients with primary vitreoretinal lymphoma. Graefes Arch Clin Exp Ophthalmol. 2014;252:687-693.

21. Akiyama H, Takase H, Kubo F, Miki T, Yamamoto M, Tomita M, et al. High-dose methotrexate following intravitreal methotrexate administration in preventing central nervous system involvement of primary intraocular lymphoma. Cancer Sci. 2016;107:1458- 1464.

22. Houillier $\mathrm{C}$, Soussain $\mathrm{C}$, Ghesquières $\mathrm{H}$, Soubeyran $\mathrm{P}$, Chinot $\mathrm{O}$, Taillandier L, et al. Management and outcome of primary CNS lymphoma in the modern era: An LOC network study. Neurology. 2020;94:1027- 1039.

23. Merle - Béral H, Davi F, Cassoux N, Baudet S, Colin C, Gourdet T, et al. Biological diagnosis of primary intraocular lymphoma. Br J Haematol. 2004;124:469- 473.

24. Cassoux N, Giron A, Bodaghi B, Tran THC, Baudet S, Davy F, et al. IL-10 measurement in aqueous humor for screening patients with suspicion of primary intraocular lymphoma. Invest Ophthalmol Vis Sci. 2007;48:3253- 3259.

25. Pochat-Cotilloux $C$, Bienvenu J, Nguyen A-M, Ohanessian $R$, Ghesquières $H$, Sève $P$, et al. Use of a threshold of interleukin-10 and il-10/il-6 ratio in ocular samples for the screening of vitreoretinal lymphoma. Retina Phila Pa. 2018;38:773- 781.

26. Abrey LE, Batchelor TT, Ferreri AJM, Gospodarowicz M, Pulczynski EJ, Zucca E, et al. Report of an international workshop to standardize baseline evaluation and response criteria for primary CNS lymphoma. J Clin Oncol Off J Am Soc Clin Oncol. 2005;23:5034- 5043.

27. Grimm SA, Pulido JS, Jahnke K, Schiff D, Hall AJ, Shenkier NT, et al. Primary intraocular lymphoma an International Primary Central Nervous System Lymphoma Collaborative Group Report. 2007;18:1851-1855.

28. Castellino A, Pulido JS, Johnston PB, Ristow KM, Nora Bennani N, Inwards DJ, et al. Role of 
systemic high-dose methotrexate and combined approaches in the management of vitreoretinal lymphoma: A single center experience 1990-2018. Am J Hematol. 2019;94:291-298.

29. Cheah CY, Milgrom S, Chihara D, Gombos DS, Pinnix CC, Dabaja BS, et al. Intensive chemoimmunotherapy and bilateral globe irradiation as initial therapy for primary intraocular lymphoma. Neuro-Oncol. 2016;18:575- 581.

30. de Smet MD, Stark-Vanes V, Kohler DR, Smith J, Wittes R, Nussenblatt RB. Intraocular Levels of Methotrexate After Intravenous Administration. Am J Ophthalmol. 121, 442- 444 (1996).

31. Batchelor TT, Kolak G, Ciordia R, Foster CS, Henson JW, High-dose methotrexate for intraocular lymphoma. 2003;9:711-715.

32. Saleh M, Nikolitch K, Bourcier T, Speeg C, Gaucher D. Repeated IL-10 measurement in aqueous humor and OCT imaging are valuable tools to monitor intraocular lymphoma treated with intravitreal injections of methotrexate. Graefes Arch Clin Exp Ophthalmol. 2012;250:761- 764.

33. Ma W-L, Hou H-A, Hsu Y-J, Chen Y-K, Tang J-L, Tsay W, et al. Clinical outcomes of primary intraocular lymphoma patients treated with front-line systemic high-dose methotrexate and intravitreal methotrexate injection. Ann Hematol. 2016;95:593-601.

34. Costopoulos M, Touitou V, Golmard J-L, Darugar A, Fisson S, Bonnemye P, et al. ISOLD: A New Highly Sensitive Interleukin Score for Intraocular Lymphoma Diagnosis. Ophthalmology. 2016;123:1626- 1628.

35. Raja H, Snyder MR, Johnston PB, O'Neill BP, Caraballo JN, Balsanek JG, et al. Effect of intravitreal methotrexate and rituximab on interleukin-10 levels in aqueous humor of treated eyes with vitreoretinal lymphoma. PloS One. 2013;8:e65627.

36. Kawamura H, Yasuda N, Kakinoki M, Sawada T, Sawada O, Ohji M. Interleukin-10 and interleukin- 6 in aqueous humor during treatment of vitreoretinal lymphoma with intravitreally injected methotrexate. Ophthalmic Res. 2009;42:172- 174.

37. de la Fuente MI, Alderuccio JP, Reis IM, Omuro A, Markoe A, Echegaray JJ, et al. Bilateral radiation therapy followed by methotrexate-based chemotherapy for primary vitreoretinal lymphoma. Am J Hematol. 2019;94:455- 460.

38. Kaburaki T, Taoka K, Matsuda J, Yamashita H, Matsuda I, Tsuji H, et al. Combined intravitreal methotrexate and immunochemotherapy followed by reduced-dose whole-brain radiotherapy for newly diagnosed B-cell primary intraocular lymphoma. Br J Haematol. 2017;179:246- 255.

39. Soussain C, Choquet S, Blonski M, Leclercq D, Houillier C, Rezai K, et al. Ibrutinib monotherapy for relapse or refractory primary CNS lymphoma and primary vitreoretinal lymphoma: Final analysis of the phase II « proof-of-concept » iLOC study by the Lymphoma study association (LYSA) and the French oculo-cerebral lymphoma (LOC) network. Eur J Cancer. 2019;117:121- 130. 40. Ghesquieres H, Chevrier M, Laadhari M, Chinot O, Choquet S, Moluçon-Chabrot C, et al. Lenalidomide in combination with intravenous rituximab (REVRI) in relapsed/refractory primary CNS lymphoma or primary intraocular lymphoma: a multicenter prospective « proof of concept » phase II study of the French Oculo-Cerebral lymphoma (LOC) Network and the Lymphoma Study Association (LYSA)†. Ann Oncol Off J Eur Soc Med Oncol. 2019;30:621- 628.

41. Baron M, Belin L, Cassoux N, Fardeau C, Blaizeau M, Soussain C, et al. Temozolomide is 
effective and well tolerated in patients with primary vitreoretinal lymphoma. Blood. 2020;135:18111815.

42. Grommes C, Tang SS, Wolfe J, Kaley TJ, Daras M, Pentsova El, et al. Phase $1 \mathrm{~b}$ trial of an ibrutinib-based combination therapy in recurrent/refractory CNS lymphoma. Blood. 2019;133:436- 445.

Table 1. Patients' characteristics at diagnosis and first-line treatment protocols. IL-6: interleukin6, IL-10: interleukin-10, MTX : methotrexate.

Table 2. Main outcomes. IL-10 : interleukin-10

Table 3. Prognostic factors. PVRL: primary vitreoretinal lymphoma. MTX: methotrexate. OS: overall survival.

Figure 1. Overall survival, brain-free survival, ocular-free survival and progression-free survival of primary vitreoretinal lymphoma (PVRL).

Supplementary Table 1: Literature review on primary vitreoretinal lymphoma (PVRL) treatment strategies and outcomes

Supplementary Figure 1: Overall survival of primary vitreoretinal lymphoma (PVRL) according to the age (yo $=$ years old) $\left(p=0.01^{*}\right)$ and the dose of methotrexate per injection $\left(\mathrm{g} / \mathrm{m}^{2}\right)$ $\left(p=0.003^{*}\right)$ 
Progression-free survival



Ocular-free survival

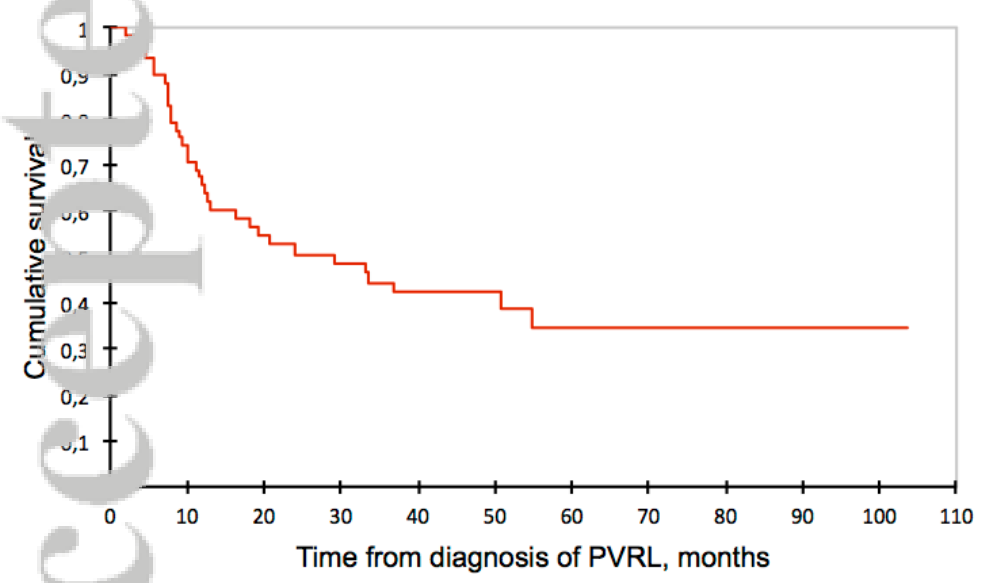

Overall survival

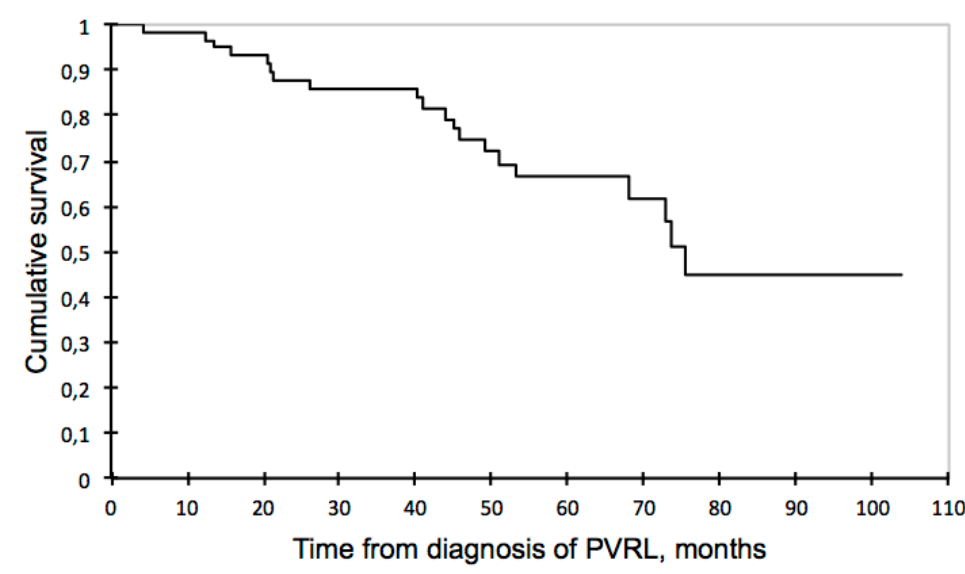

Brain-free survival

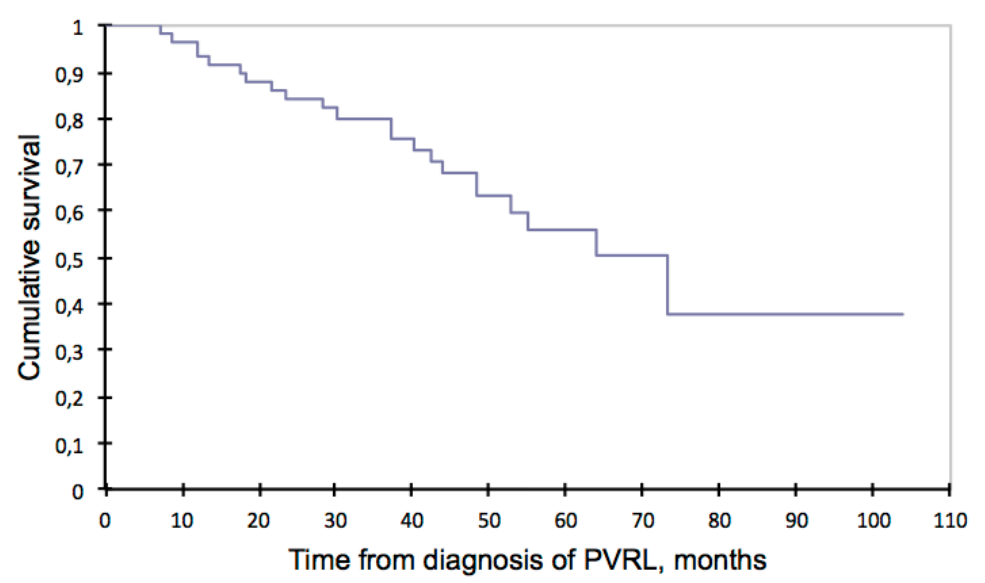

AJH_26199_Figure 1.tiff 
Table 1. Patients' characteristics at diagnosis and first-line treatment protocols. IL-6: interleukin6, IL-10: interleukin-10, MTX : methotrexate.

\begin{tabular}{|c|c|}
\hline $\mathbf{N}$ & 59 \\
\hline Age, median (range), y & $70(39-88)$ \\
\hline Sex M/F & $14 / 45$ \\
\hline Bilaterality & $39 / 59(66 \%)$ \\
\hline \multicolumn{2}{|l|}{ Initial visual symptoms } \\
\hline Decreased visual acuity & $49 / 57(86 \%)$ \\
\hline Myodesopsia & $10 / 57(18 \%)$ \\
\hline Asymptomatic & $1 / 57(2 \%)$ \\
\hline $\begin{array}{l}\text { Median best corrected visual acuity of affected eyes at } \\
\text { diagnosis ( } 95 \text { eyes), logMAR }\end{array}$ & $0.22(0-2.3)$ \\
\hline Missing data & 2 patients (3 eyes) \\
\hline Vitreous haze at diagnosis & $54 / 56(96 \%)$ \\
\hline Median grade of vitreous haze & 2 \\
\hline Karnofsky performance status score, median (range) & $90 \%(60-100)$ \\
\hline Median time to diagnosis (range), months & $8.7(0,8-57)$ \\
\hline \multicolumn{2}{|l|}{ Cytopathology } \\
\hline Diffuse large B-cell lymphoma & $57 / 59(97 \%)$ \\
\hline Unclassifiable B-cell lymphoma & $2 / 59(3 \%)$ \\
\hline Lumbar puncture performed & $48 / 55(87 \%)$ \\
\hline \multicolumn{2}{|l|}{ Results of the lumbar puncture } \\
\hline Normal & $38 / 48(79 \%)$ \\
\hline Lymphomatous cells (cytology or flow cytometry) & $4 / 48(8 \%)$ \\
\hline Uncertain results & $2 / 48(4 \%)$ \\
\hline Unknown results & $4 / 48(8 \%)$ \\
\hline \multicolumn{2}{|l|}{ IL6 and IL10 cytokines in the aqueous humor } \\
\hline Number of data available & $44 / 59$ \\
\hline IL10 level (pg/ml): median (range) & $202(2.5-8867)$ \\
\hline Elevated IL10 (>30pg/ml) & $39 / 44(89 \%)$ \\
\hline$\%$ of positive ISOLD score (Costopoulos et al.(35)) & $38 / 44(86 \%)$ \\
\hline IL10/IL6 ratio (>1) & $35 / 44(80 \%)$ \\
\hline \multicolumn{2}{|l|}{ IL6 and IL 10 cytokines in the vitreous } \\
\hline Number of data available & $47 / 59$ \\
\hline IL10 level (pg/ml): median (range) & $577(2.5-6179)$ \\
\hline Elevated IL10 (>65pg/ml) (\%) & $42 / 47(89 \%)$ \\
\hline$\%$ of positive ISOLD score (Costopoulos et al. (35) ) & $36 / 39(92 \%)$ \\
\hline IL10/IL6 ratio $(>1)$ & $37 / 39(95 \%)$ \\
\hline \multicolumn{2}{|l|}{ Type of treatment } \\
\hline $\mathrm{MTX} \geq 3 \mathrm{~g} / \mathrm{m} 2$ & $52 / 59(88 \%)$ (range 3-8) \\
\hline MTX 1-2g/m2 (mean 1.5g/m2) & $7 / 59(12 \%)$ \\
\hline
\end{tabular}




\section{Protocols}

(Rituximab), methotrexate, etoposide, carmustin, prednisone, (cytarabine) ((R)-MBVP-(A))

$11 / 59(19 \%)$

(Rituximab), methotrexate, vincristine, procarbazine, cytarabine ((R)-MPVA)

$35 / 59(59 \%)$

(Rituximab), methotrexate, cytarabine

$11 / 59(19 \%)$

Other $2 / 59(3 \%)$

Use of rituximab $39 / 59(66 \%)$

Autologous stem cell graft $1 / 59(2 \%)$

Associated local treatment

Ocular radiotherapy 30 Gy

$6 / 59(10 \%)$

Intravitreal MTX 
Table 2. Main outcomes. IL-10 : interleukin-10

Response to chemotherapy at two months, n (\%)

Complete or uncertain complete response (CR/uCR)

21/52 (40\%) patients

Partial response (PR)

26/52 (50\%) patients

Stable disease (SD)

$3 / 52(6 \%)$ patients

Progressive disease (PD)

$2 / 52(4 \%)$ patients

Assessable final response to $1^{\text {st }}$ line

chemotherapy, n (\%)

57 patients - 95 eyes

CR/UCR

PR

40/57 (70\%) - 71/95 (75\%)

$3 / 57(5 \%)-4 / 95(4 \%)$

$1 / 57(2 \%)-2 / 95(2 \%)$

PD

$13 / 57(23 \%)-18 / 95$ (19\%)

Missing data

2 patients ( 1 death, 1 missing data) - 3 eyes

Visual acuity of affected eyes after chemotherapy, median, logMar (range)

$0.10(0-2.3)$

Improvement, $\mathrm{n}$ eyes (\%)

$41 / 83(50 \%)$

Stability, $n$ eyes $(\%)$

$25 / 83(30 \%)$

Worsening, $n$ eyes $(\%)$

$17 / 83(20 \%)$

Missing data, $n$ eyes

15

IL-10 in the aqueous humor at final

response to $1^{\text {st }}$ line chemotherapy $(n=37), n$

(\%)

in patients with $\mathrm{CR} / \mathrm{uCR}$

Detectable IL-10

$3 / 23(13 \%)$

Undetectable IL-10

20/23 (87\%)

in patients with $\mathrm{PR}$

Detectable IL-10

$0 / 1(0 \%)$

Undetectable IL-10

$1 / 1(100 \%)$

in patients with SD/PD

Detectable IL-10

$12 / 13(92 \%)$

Undetectable IL-10

$1 / 13(8 \%)$

Grade III-IV toxicities of chemotherapy, $\mathrm{n}$

(\%)

Myelosuppression

$27 / 51(53 \%)$

Lymphopenia

$14 / 51(27 \%)$

Neutropenia/neutropenia with fever

$19 / 51(37 \%) / 3 / 51(6 \%)$

Thrombopenia

$14 / 51(27 \%)$

Anemia

$4 / 51(8 \%)$

Infections

$8 / 51(16 \%)$

Hepatic cytolysis

$4 / 51(8 \%)$

Renal dysfunction

$4 / 51(8 \%)$

Toxic deaths

$0 / 59$ 
Disruption of MTX due to toxicity

Ocular toxicity of local treatment

Intravitreal MTX $(n=2)$

Cataract

Keratopathy

Ocular radiotherapy $(n=6)$

Dry eyes

Cataract

Radiation retinopathy

Macular edema

Number of patients who relapsed, $\mathbf{n}(\%)$

Only ocular relapse(s)

Only cerebral relapse(s)

Only systemic relapse(s)

Both ocular and cerebral relapse(s)

Ocular relapse first

Both ocular and cerebral relapse first

Cerebral relapse first

Ocular and systemic with/without brain

relapse(s)

\section{Side of ocular relapse}

Bilateral involvement at diagnosis

Bilateral relapse

Unilateral relapse

Unilateral involvement at diagnosis

Bilateral relapse

Unilateral relapse

In the same eye

In the other eye

Missing data

IL-10 at first ocular relapse ( $n=27), n(\%)$

Increase of IL-10 or detectable IL-10

Undetectable IL-10

Death, n (\%)

Cause of death

Lymphoma brain relapse

Cardiovascular disease
$0 / 59$

$2 / 2(100 \%)$

$1 / 2(50 \%)$

$2 / 6(33 \%)$

$3 / 6(50 \%)$

$1 / 6(17 \%)$

$1 / 6(17 \%)$

$42 / 59(71 \%)$

$17 / 59(29 \%)$

$7 / 59(12 \%)$

$1 / 59(1 \%)$

$15 / 59$ (24\%)

$12 / 15$

$2 / 15$

$1 / 15$

$2 / 59(3 \%)$

\section{4}

$12 / 24(50 \%)$

$12 / 24(50 \%)$

10

$3 / 10(30 \%)$

$6 / 10(60 \%)$

2

4

$1 / 10(10 \%)$

$25 / 27(93 \%)$

$2 / 27(7 \%)$

$20 / 59(34 \%)$

17

1 (myocardial infarction during the first line chemotherapy) 
Table 3. Prognostic factors. PVRL: primary vitreoretinal lymphoma. MTX: methotrexate. OS: overall survival.

\begin{tabular}{|c|c|c|c|c|c|}
\hline & & \multicolumn{2}{|c|}{ Univariate analysis } & \multicolumn{2}{|c|}{ Multivariate analysis } \\
\hline & $\mathrm{N}$ & Median OS & $p$ value & Hazard ratio & $p$ value \\
\hline \multicolumn{6}{|l|}{ Age } \\
\hline$\geq 70$ & 32 & 68 & $0.01^{*}$ & 3.4 & $0.05^{*}$ \\
\hline$<70$ & 27 & NR & & & \\
\hline \multicolumn{6}{|l|}{ Sex } \\
\hline Male & 14 & 74 & 0.3 & & \\
\hline Female & 45 & 75 & & & \\
\hline
\end{tabular}

Karnofsky

performance status

score

$$
\leq 80
$$

18

74

0.3

0.4

0.1

$>80$

37

75

Laterality of PVRL

$$
\text { Unilateral }
$$

20

51

0.08

37

75

Hyalitis

Yes
No

50

NR

0.4

5

NR

Best corrected visual acuity

$<3$

$\geq 3$

Meningeal disease

$$
\text { Yes }
$$

No

\section{Chemotherapy} protocols

(Rituximab),

methotrexate, etoposide, carmustin, prednisone,

(cytarabine) ((R)-MBVP-

(A))

(Rituximab),

methotrexate, vincristine, procarbazine, cytarabine ((R)-MPVA)
35

74

0.2

43

6

38

NR

0.1

75

75

0.1
(Rituximab), methotrexate, cytarabine 
Dose of MTX per injection

$\begin{array}{lccccc}\geq 3 \mathrm{~g} / \mathrm{m}^{2} & 52 & 75 & 0.003^{*} & 0.2 & 0.03^{*} \\ <3 \mathrm{~g} / \mathrm{m}^{2} & 7 & 30 & & & \end{array}$

Rituximab

$\begin{array}{llll}\text { Yes } & 39 & 73 & 0.6 \\ \text { No } & 20 & 74 & \end{array}$

Combined with local treatment

\begin{tabular}{lccc} 
Yes & 8 & 74 & 0.2 \\
No & 51 & NR & \\
\hline
\end{tabular}

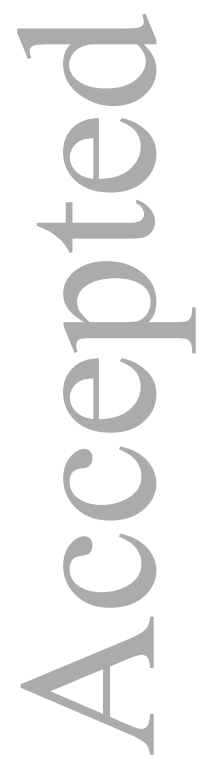

